
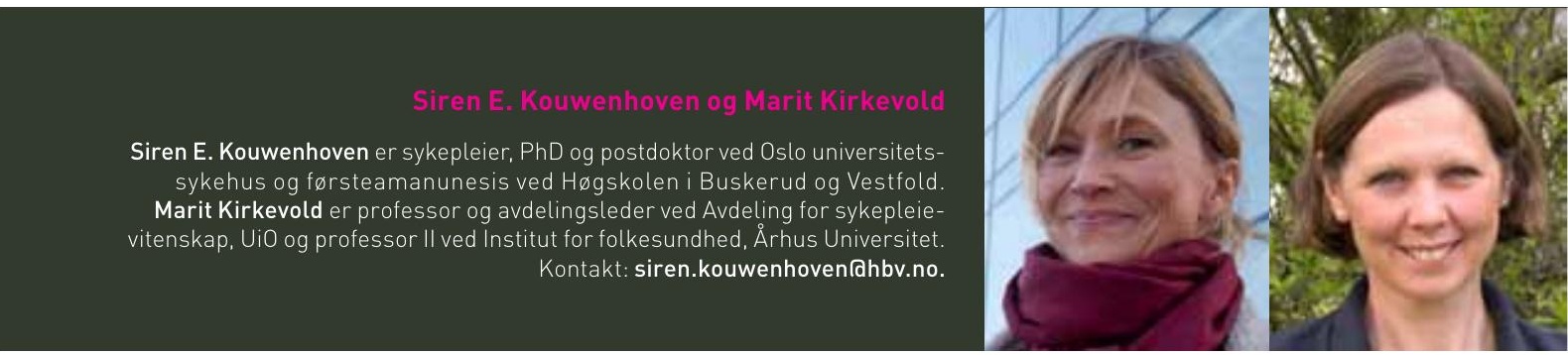

\title{
Depressive symptomer etter hjerneslag
}

\section{$>$ Er depresjon etter hjerneslag et uttrykk for sykdom eller sorg?}

Depressive symptomer er et velkjent fenomen etter hjerneslag og har vært beskrevet i den internasjonale litteraturen i mer enn hundre år (1). Likevel er fenomenet langt fra entydig. I litteraturen sammenfattes det å ha depressive symptomer, å fole seg deprimert og/eller å ha en depresjonsdiagnose etter hjerneslag, i begrepet «post-stroke depression». Det er uenighet om fenomenet er en medisinsk diagnose eller en naturlig reaksjon på en vanskelig livssituasjon. Hvordan vi forstår post-stroke depression, vil være avgjørende for hvordan vi som helsepersonell forholder oss. Det er derfor viktig å se nærmere på spørsmålet: Er depressive symptomer etter hjerneslag et uttrykk for sykdom eller sorg, eller er det fare for at man ved å kalle det sykdom medikaliserer livsverden? Dette essayet bygger både på egen forskning, og på litteratursøk knyttet til temaet.

\section{ULIKE PERSPEKTIVER}

I det norske språket bruker vi betegnelsen sykdom for å beskrive flere forskjellige sider ved det å være syk eller ha en sykdom. I det engelske språket skiller man mellom begrepene disease, illness og sickness. Vi tar utgangspunkt $\mathrm{i}$ disse tre begrepene når vi videre drøfter fenomenet (2).

- Disease-perspektivet har sitt utgangspunkt $i$ et naturvitenskapelig kunnskapssyn. Det brukes om sykdom som en kategorisert tilstand, der anatomiske, fysiologiske eller biokjemiske symptomer, årsak og virkningsmekanismer er viktige elementer (2).

- Illness-perspektivet har sitt utgangspunkt $i$ et humanvitenskapelig kunnskapssyn og beskriver hvordan den som er syk, opplever symptomer og funksjonssvikt. Illness understreker de individuelle erfaringene og påvirkes av kultur og kontekst (2).

- Sickness-perspektivet har sitt utgangspunkt i et samfunnsvitenskapelig kunnskapssyn og understreker sykdom i relasjon til sosiale, økonomiske, kulturelle, eller politiske forhold (2). Sickness danner utgangspunkt for bestemte rettigheter som sykmelding eller egenmelding.

Som regel er det samsvar mellom tilstedeværelsen av symptomer og sykdom, opplevelsen av å være syk, og at sykdommen anerkjennes og tilkjennes bestemte rettigheter i samfunnet. Men hvis ikke, kan det oppstå verdikonflikter (3). Dette gjelder for eksempel omstridte sykdommer som whiplash eller ME, der en person opplever å være syk og tilkjennes rettigheter, mens tilstanden ikke er klassifisert som sykdom. Eller ved for eksempel enkelte psykiske lidelser, som mani, der personen ikke opplever seg som syk, men har symptomer som oppfyller kriteriene for sykdom og gir rettigheter i samfunnet.

\section{DISEASE-PERSPEKTIVET}

I depresjon etter hjerneslag møtes to domener innen medisin og helsefag: Det somatiskeog det psykiske. Hjerneslaget er den utløsende årsaken og kan føre til både fysiske-, kognitive-, 


\section{Få studier har fokusert på den deprimerte slagrammedes erfaring spesielt.}

kommunikative- og emosjonelle symptomer.

Det er de samme symptomene som danner grunnlag for diagnose ved depresjon etter hjerneslag, som ved annen depresjonssykdom, og diagnosen bygger på personens beskrivelse av bestemte symptomer. Symptomene kategoriseres gjerne som milde, moderate eller alvorlige. Depressive symptomer kan kartlegges med ulike typer kartleggingsskjemaer, men resultatet av disse kan ikke danne grunnlag for en depresjonsdiagnose. Kartleggingsverktøyene benyttes både $\mathrm{i}$ klinisk praksis og $\mathrm{i}$ utstrakt grad innen forskning.

Depresjonsdiagnose stilles av lege, psykolog eller psykiater. I tillegg til at flere depressive symptomer skal være til stede samtidig, er det viktig hvordan symptomene virker inn på personens dagligliv, sosiale liv og ellers hvordan personen fungerer. Det finnes to diagnosesystemer for psykiske diagnoser, det europeiskbaserte ICD-10 og det amerikanske DSM V. Det er stor grad av samsvar mellom dem, men mens depresjon etter hjerneslag er en egen kategori i DSM V, eksisterer denne ikke i ICD-10. I Norge er det ICD-systemet som benyttes i klinikken, mens DSMsystemet ofte benyttes i internasjonal forskning.

\section{FOREKOMST OG ÅRSAK}

Det er gjort mye forskning på depresjon etter hjerneslag med utgangspunkt i disease-perspektivet. I overkant av 30 prosent av slagrammete har depresjon/ depressive symptomer inntil fem år etter et hjerneslag (4). Litteraturen presenterer to forklaringsmodeller for fenomenet. Den ene ser på patofysiologiske mekanismer som årsaken, den andre peker på at depresjon etter hjerneslag er en psykososial reaksjon. I fag- og forskningslitteratur regnes depressive symptomer etter hjerneslag i hovedsak som disease, uavhengig av hvordan årsaksmekanismene forklares (4).

Forskningslitteraturen vedrørende patofysiologiske mekanismer, har i særlig grad sett på hjerneskadens plassering, omfang eller art. Flere oversiktsartikler i anerkjente tidsskrifter har sammenfattet forskningen på feltet, men fremdeles er mye uklart rundt de patofysiologiske mekanismene (5-8).

Forskningslitteraturen med den psykososiale forklaringsmodellen, har i stor grad handlet om assosierte faktorer og disposisjoner. Tidligere historie med depresjon, dysfagi, funksjonssvikt, det å leve alene eller være sosialt isolert (9), alvorlig slag (10) og kognitiv svikt (11) er risikofaktorer. Whyte and Mulsant har tatt for seg evidensen for og mot en biologisk forklaringsmodell (12). De konkluderte med at depresjon etter hjerneslag bør ses på som et multifaktorielt fenomen i samsvar med en biopsykososial modell for psykiske lidelser.

Et annet forhold som gjør depresjon etter hjerneslag så komplekst, er at symptomer på depresjon kan være overlappende med andre konsekvenser etter slaget, som forstyrret søvnfunksjon, nedsatt appetitt, mangel på energi og besluttsomhet, eller nedsatt konsentrasjon. Når en depresjonsdiagnose skal stilles hos slagrammete, er det derfor mange hensyn å ta. Skal alle symptomer telle selv om de kanskje kan være et resultat av slaget selv, eller skal man bare anerkjenne symptomer som ikke kan anses som direkte følge av slaget? Og hvordan kan man egentlig skille mellom disse? (13). Dette er viktige og vanskelige spørsmål.

\section{FOREBYGGING \\ OG BEHANDLING}

Det benyttes ulike typer av tiltak for å forhindre eller behandle depresjon etter hjerneslag. Psykologiske intervensjoner kan redusere risiko for depresjon etter hjerneslag, men det er begrenset evidens for at medikamenter kan ha forebyggende effekt (14). Behandling av depresjon etter slag, kan også gjøres på ulike måter. Medikamentell behandling kan ha effekt på alvorlig depresjon etter hjerneslag, men evidensen er svak (15) og bivirkningene mange $(16,17)$. For mildere depresjon finnes det ingen evidens for medikamentell behandling.

Studier viser at Elektrosjokkbehandling (ECT) kan være effektivt i noen tilfeller av alvorlig depresjon etter hjerneslag. 
Men mange pasienter får betydelige komplikasjoner etter denne type behandling, og den er ikke anbefalt for eldre slagrammete (17). Også ulike samtalebaserte intervensjoner har vært benyttet som behandling mot depresjon etter slag (18), men heller ikke her finnes det evidens for at psykoterapi alene, har behandlingseffekt. Andre effektive intervensjoner er «life review»terapi, motiverende samtale, fysisk aktivitet, informasjon og spesifikke sykepleieprogrammer. Noen har kombinert antidepressiva med psykososial intervensjon og funnet at dette har større effekt enn antidepressiva alene. Studiene er imidlertid små og resultatene begrenset (19).

Ut fra det rådende synet på hva depresjon etter hjerneslag er, kan vi slå fast at fenomenet kan klassifiseres som en disease. Men mye av mekanismene rundt årsaker, virkninger og behandling er fremdeles uklare, og det er grunn til å stille spørsmål ved hvordan symptomene kartlegges, vurderes og vektes.

\section{ILLNESS-PERSPEKTIVET}

For at illness-perspektivet skal få innhold, må man gå til personen som opplever symptomene. Selv om illness er et individuelt perspektiv, kan man tenke seg at det vil være noe ved erfaringen som er fellesmenneskelig (20). Det er gjort flere studier av den levde erfaringen med hjerneslag. Tap er et tema som går igjen i flere studier (21). Andre opplevelser er endrete roller, fremmedgjøring av kroppen og forandret opplevelse av seg selv og ens identitet (22-24).

\section{DEN SLAGRAMMEDES ERFARING}

Få studier har fokusert på den deprimerte slagrammedes erfaring spesielt. I 2004 undersøkte Robinson-Smith (25) dette med utgangspunkt i kartleggingsverktøy for depresjon. Hun fant fem overordnete temaer: a) å vende seg mot negative følelser, b) å ha nattlige symptomer, c) opplevelse av endring i kroppssensitivitet, d) føle seg nedfor, e) behov for spirituell hjelp. Med utgangspunkt i dette, foreslo hun at det bør utvikles bedre kartleggingsinstrumenter, spesielt med tanke på spiritualitet.

I 2010 publiserte Townend og kollegaer (26) en studie der de undersøkte sammenhengen mellom depresjon og aksept av funksjonssvikt. De så på hvordan slagrammete forholder seg til funksjonssvikt. Deltakere både med og uten depresjon, ble inkludert og sammenliknet. Gjennom intervjuene fant forskerne at deprimerte informanter, i motsetning til ikkedeprimerte, var opptatt av at de fremdeles burde være i stand til å utføre det de kunne før. De beskrev seg selv som unyttige og ga uttrykk for tristhet og frustrasjon, slik som «å føle seg fanget» og «hjelpeløs», i relasjon til andre.

I vår tidligere studie fulgte vi en gruppe slagrammete, som alle hadde depressive symptomer i akuttfasen etter hjerneslaget, med dybdeintervjuer ved en, seks, 12 og 18 måneders tidspunkt (27-29).

På direkte spørsmål bekreftet deltakerne at de opplevde depressive symptomer, men de forsto, beskrev og forklarte dem ut fra endringene etter slaget. De depressive symptomene og konsekvensene av slaget var vevd sammen. Det var som om depresjonssymptomene dannet et utgangspunkt for fortellingen om slaget. Tap var en vesentlig del av informantenes fortelling. De depressive symptomene var i sterk grad knyttet til å håndtere, akseptere og leve med tap. Livssituasjon, grad av nedsatt funksjon og sosial kontekst så ut til å påvirke hvordan depresjonen endret seg over tid. Depressive symptomer var til stede hos alle, men i ulik grad, og varierte i løpet av 18 måneder (30).

Horwitz og Wakefield (31) hevder at depressive symptomer ofte er beskrevet som symptomer «uten årsak», det vil si at personen ikke kan peke på grunnen til at han er lei seg, grunnen til at han ikke har matlyst og så videre. Men det var nettopp det deltakerne i vår studie gjorde. De pekte på tapene ved hjerneslaget som årsaken til symptomene. Deltakernes sterke fokusering på både synlige og usynlige tap, og deres måte å beskrive de depressive symptomene på, samt deres beskrivelse 
De depressive symptomene og konsekvensene

av slaget var vevd sammen.

av dette som en naturlig reaksjon på en utfordrende, vanskelig og kritisk situasjon, fikk oss til å stille spørsmålet om dette var en sorgreaksjon.

\section{SORG OG DEPRESJON}

Det meste av sorglitteraturen omhandler sorg etter tap av en nær pårørende, men hos Sandvik (32) defineres sorg videre: «Sorg er reaksjoner på betydningsfulle tapsopplevelser (..) som i vesentlig grad innvirker på personens grunnleggende livssituasjon og opplevelse av hva livet dreier seg om (..) Sorg er også betegnelsen på den langsiktige tilpasningsprosessen som innebærer å akseptere tapet og konsekvensene av det, og leve videre i lys av dette» (s. 16). Noen få studier har pekt på sammenhengen mellom sorg og hjerneslag (33-35), og beskrevet at sorg etter hjerneslag ikke skiller seg fra sorg etter en nær pårørende (36).

Ifølge Bonanno og Kaltmann (37) kan sorg defineres som en sammensatt respons på tap i månedene etter tapet. De framhever symptomer som problemer med konsentrasjon, vanskeligheter med å ta valg, opplevelse av tapt identitet og avbrutt framtid, langvarig søk etter mening, og stor grad av tristhet.

Det er mange som har diskutert forholdet mellom klinisk depresjon og «normal tristhet», som for eksempel sorg. Clayton fant at opptil 42 prosent av sørgende oppfylte kriteriene for depressiv sykdom en måned etter tapet, og at 16 prosent også oppfylte depresjonskriteriene etter ett år (38). Dette er støttet av andre studier $(37,39)$. Horwitz og Wakefield (31) beskriver at "normal tristhet» er karakterisert ved den spesifikke konteksten det oppstår i, at intensiteten henger sammen med opplevelsen av selve tapet, og at den gradvis opphører etter hvert som mestringsmekanismer inntrer. Flere har pekt på kontekst som vesentlig når de to fenomenene skal skilles fra hverandre.

Ved tap av pårørende, er det en som står nær som er borte, mens deltakerne i vår studie beskrev opplevelsen av å ha mistet seg selv, føle seg fanget i egen kropp eller i omgivelsene etter hjerneslaget. Ved hjerneslag er ikke tapet nødvendigvis permanent eller endelig. Muligheten for å gjenvinne større eller mindre deler av det som er tapt vil være der i uker, måneder og år etter hjerneslag. Balansen mellom tap og å akseptere det på den ene siden, og gjenvinne funksjon på den andre siden, er vesentlig og vanskelig.

Til tross for begrensningene som ligger i vår studie, blant annet at det er et lite utvalg, tyder funnene på at depresjon etter hjerneslag fra et illnessperspektiv kan ses på som en naturlig sorgreaksjon. Med utgangspunkt i illness-perspektivet kan man hevde at depres- sive symptomer etter hjerneslag kan være en naturlig sorgreaksjon.

\section{SICKNESS-PERSPEKTIVET}

Sickness-perspektivet, hva vi som samfunn ser på som normalt og unormalt, friskt eller sykt, kommer til uttrykk gjennom forestillinger, holdninger og normer og er ikke statisk. Det er ikke bare fordi vitenskapen og forskningen går framover, men det er også kultur-og kontekstavhengig $(2,3)$.

Vi har ikke funnet litteratur som spesifikt drøfter sicknessperspektivet på depresjon etter hjerneslag. Flere studier har imidlertid beskrevet opplevelsen av stigmatisering og marginalisering både hos mennesker som har psykiske lidelser som depresjon, og hos mennesker med hjerneslag (40-44). Flere studier har dessuten framhevet hvordan relasjoner til andre kan forandre seg etter hjerneslag. Endret opplevelse av seg selv, egen identitet og verdi står sentralt (45-47).

I vår studie ble det benyttet kartleggingsverktøy for depresjon, og i henhold til disse beskrev deltakerne depressive symptomer. På spørsmålet om deltakerne opplevde seg som deprimerte, svarte flere derimot avkreftende. En av deltakerne som skåret høyt på depresjonsskjemaene og beskrev depressive symptomer gjennom hele forløpet, sa: «(..) å gå å deppe og sånn er jo bare tull. Blir 
ikke noe bedre av det. Både for omgivelsene og deg sjøl.» Det kan være mange årsaker til at hun ikke selv regnet seg som deprimert. Det handlet kanskje om det som kan kalles et responsskifte eller en tilpasning til situasjonen (48). Eller kanskje det handlet om hennes forestillinger om hvordan en som er deprimert, skal være, eller at hun opplevde at de depressive symptomene hun hadde, var uttrykk for noe annet, som sorg. Det er også mulig at det å være deprimert for henne var forbundet med skam, eller at hun vegret seg for selve diagnosen, slik stigmalitteraturen vektlegger. Men hvorfor det var slik for henne, spiller egentlig ikke så stor rolle her. Poenget er at disease-kriteriene og illness, det levde livs erfaringer, ikke stemte over ens. På en side kan man si at det ikke kan forventes at den som er syk og har symptomer på en sykdom, skal kunne "stille diagnosen selv», men på den andre siden er det jo en psykiatrisk diagnose, nettopp basert på pasientens egen opplevelse. Hvor går grensene når det er diskrepans mellom illness og disease-perspektivet? Og hva skal vektes tyngst?

\section{MEDIKALISERING}

Kritiske samfunnsrøster og fagmiljøer har i mange år advart mot en biologisering og «medikalisering» av psykiske lidelser (49-51). Medikalisering forstås som at normalt forekommende menneskelige variasjoner, plager og funksjonsvansker defineres som medisinske tilstander $(50,52)$. Den franske filosofen Foucault framhevet at den medisinske persepsjonen ikke bare er formet av den generelle kulturen, men også i høy grad former kulturen (53). I dag inneholder diagnosesystemet DSM V mer enn 340 psykiatriske diagnoser. Dette en økning på over 300 prosent siden den første diagnosemanualen, DSM I, kom i 1952 (51). Forekomsten av depresjon har økt betraktelig og er beskrevet som det største folkehelseproblemet i den vestlige verden (54). Fra 1970-tallet og fram til i dag har det vært en sterk økning i bruken av de fleste typer psykofarmaka i alle de nordiske landene (54). Kringlen (49) advarer mot at en biologisering kan føre til at vi mister fokus på pasienten som person. Han er dessuten svært kritisk til koplingen mellom den farmasøytiske industrien og psykiatrien, spesielt i USA, som er ledende i verdenssammenheng. I 2001 brukte legemiddelselskapene rundt 11 milliarder dollar på gratis prøver til leger, 2,7 milliarder dollar på reklame direkte rettet mot forbrukerne, og 380 millioner dollar på annonser i medisinske tidsskrifter. Bare i Norge ble det i 2004 brukt mer enn 500 millioner kroner på markedsføring til leger (49).

Ut fra sickness-perspektivet er det naturlig å spørre om depresjon etter hjerneslag er sykdom, eller om naturlig tristhet og sorgreaksjon for kjapt underlegges en medisinsk diskurs? Eller er det slik at et naturlig livsfenomen blir til noe sykt fordi det ikke lenger er rom for det vi før beskrev som naturlige reaksjoner?

\section{SYKDOM, SORG ELLER MEDIKALISERING?}

Studier har pekt på at illnessperspektivet blir oversett når helsepersonell møter slagrammete. I slagrehabilitering har helsepersonell ofte et biomedisinsk perspektiv med en hovedinteresse i å organisere, kartlegge og tilrettelegge rehabiliteringsaktiviteter, mens pasientens perspektiv både omfatter det biomedisinske, det sosiale og det psykiske (55-58). Den slagrammete er avhengig av både det helsepersonell gjør, og hva slags informasjon de gir og ikke gir. Dette er viktige elementer for illness-perspektivet og hvordan den slagrammete ser på seg selv og sin situasjon, skaper mening, forventninger og motivasjon (58).

Det at illness-perspektivet overses og disease-perspektivet dominerer, handler om hva vi som samfunn vektlegger og hva slags posisjon ulike kunnskapssyn har i samfunnet. Men på den andre siden har flere beskrevet diskrepansen mellom den objektive manifestasjonen og den subjektive erfaringen i depresjon, og framhevet dette 
som et problem $\mathrm{i}$ forståelsen av depresjon (59-61).

Problemstillingen for vår artikkel legger opp til et enten eller: Depresjon etter hjerneslag er enten sykdom i en diseaseforstand, eller en normal reaksjon med elementer av naturlig sorg. Men slik vi ser det, er både disease-perspektivet, illness-perspektivet og sicknessperspektivet virksomme i depresjon etter hjerneslag. På bakgrunn av den naturvitenskapelige kunnskapen, kan vi ikke avvise at dette er sykdom. Med ut fra et humanvitenskapelig perspektiv, kan vi ikke avvise at depressive symptomer er en naturlig reaksjon preget av sorg over det som er tapt. Og ut fra et samfunnsvitenskapelig syn, må vi også forholde oss til den kontekst fenomenet oppstår i, og den kontekst hver enkelt slagrammet lever i. Men det ene utelukker ikke nødvendigvis det andre. Fenomenet depressive symptoner etter hjerneslag kan være flere ting, og flere ting på en gang.

Hvorfor er det egentlig viktig å avklare dette spørsmålet? Depressive symptomer etter hjerneslag kan være avgjørende for hvordan det går med den slagrammete, og symptomene må derfor ivaretas og følges opp. Forskningen som er gjort på feltet, har i stor grad vært konsentrert rundt diseaseperspektivet, mens få har sett på fenomenet fra et illness-og sickness-perspektiv. Og kanskje er det nettopp fordi synet har vært så ensidig, at forskningen har kommet så kort i forståelsen av dette fenomenet?

\section{REFERANSER}

1. Robinson R. The clinical neuropsychiatry of stroke: cognitive, behavioral and emotional disorders following vascular brain injury. 2nd ed. Cambridge: Cambridge University Press; 2006.

2. Kleinman A. The illness narratives. New York: Basic Books Inc. Publishers: 1988

3. Hofmann B. Hva er sykdom? Oslo: Gyldendal Akademisk; 2008.

4. Hackett ML, Yapa C, Parag V, Anderson CS. Frequency of depression after stroke: a systematic review of observational studies. Stroke. 2005;36:1330-40. 5. Bhogal SK, Teasell R, Foley N, Speechley M. Lesion location and poststroke depression: systematic review of the methodological limitations in the literature. Stroke. 2004:35:794-802.

6. Hackett ML, Glozier NS, House AO. Moving the ambulance to the top of the cliff: reducing the burden of depressive symptoms after stroke. International Journal of Stroke. 2009:4:180-2

7. Carson A, MacHale S, Allen K, Lawrie S, Dennis M, House A, et al. Depression after stroke and lesion location: a systematic review. Lancet. 2000;356:122-6. 8. Narushima K, Kosier JT, Robinson RG. A reappraisal of poststroke depression, intra- and inter-hemispheric lesion location using meta-analysis. Journal of Neuropsychiatry \& Clinical Neurosciences. 2003;15:422-30.

9. Ouimet M, Primeau F, Cole M. Psychological risk factors in poststroke depression: a systematic review. Canadian Journal of Psychiatry. 2001;46:81928.

10. Hackett M, Anderson C. Predictors of depression after stroke: a systematic review of observational studies. Stroke. 2005;36:2296-301.

11. Johnson J, Minarik P, Nystrom K, Bautista C, Gorman M. Poststroke depression incidence and risk factors: an integrative literature review. J Neurosci Nurs. 2006;38:316-27.
12. Whyte E, Mulsant B. Post Stroke Depression: Epidemiology, Pathophysiology, and Biological Treatment. Society of Biological Psychiatry 2002;52:253-64.

13. Starkstein SE, Lischinsky A. The phenomenology of depression after brain injury. NeuroRehabilitation. 2002;17:105-13.

14. Hackett ML, Anderson CS, House A, Halteh C. Interventions for preventing depression after stroke. Cochrane Database of Systematic Reviews. 2008:CD003689.

15. Hackett ML, Anderson CS, House A, Xia J. Interventions for treating depression after stroke. Cochrane Database of Systematic Reviews. 2008:CD003437. 16. Hackett ML, Anderson CS, House AO. Intervention for treating depression after stroke. Cochrane Database Syst Rev. 2009 (1).

17. Hackett ML, Anderson CS. Treatment options for post-stroke depression in the elderly. Journal of Aging Health. 2005;1:95-105.

18. de Man-van Ginkel JM, Gooskens F, Schuurmans MJ, Lindeman E, Hafsteinsdottir TB, Rehabilitation Guideline Stroke Working G. A systematic review of therapeutic interventions for poststroke depression and the role of nurses. Journal of Clinical Nursing. 2010;19:3274-90.

19. Mitchell $P$, Veith $R$, Becker $K$, Buzaitis A, Cain K, Fruin M, et al. Brief Psychosocial-Behavioral Intervention With Antidepressant Reduces Poststroke Depression Significantly More Than usual Care With Anidepressant. Stroke. 2009:40:3073-8

20. van Manen $M$, editor. Researhing Lived Experience. Human Science for an Action Sensitive Pedagogy. 2nd ed. Ontario, Canada: The Althouse Press; 1997

21. Salter K, Hellings C, Foley N, Teasell R. The experience of living with stroke: a qualitative meta-synthesis. Journal of Rehabilitation Medicine. 2008;40:595-602.

22. McKevitt C, Redfern J, Mold F, Wolfe C. Qualitative studies of stroke: a systematic review. Stroke. 2004:35:1499-505. 23. Coker E. After a stroke, women described changes that created a sense of bodily strangeness. Evidence-Based Nursing. 2004;7:92. 
24. Kvigne K, Kirkevold M. Living with bodily strangeness: women's experiences of their changing and unpredictable body following a stroke. Qualitative Health Research. 2003;13(9):1291-310. 25. Robinson-Smith G. Verbal indicators of depression in conversations with stroke survivors. Perspectives in Psychiatric Care 2004;40:61-9.

26. Townend E, Tinson D, Kwan J, Sharp M. 'Feeling sad and useless': an investigation into personal acceptance of disability and its association with depression following stroke. Clinical Rehabilitation. 2010;24:555-64

27. Kouwenhoven S, Kirkevold M. Å leve med depresjon etter hjerneslag. Sykepleien forskning. 2013; 4: 334-343.

28. Kouwenhoven SE, Kirkevold M Engedal K, Biong S, Kim H. The lived experience of depressive symptoms after stroke - a longitudinal perspective. International Journal of Qualitative Studies on Health and Well-being. 2011;6(4) Epub doi: 10.3402/qhw.v6i4.8491.Epub 2011 Dec 7

29. Kouwenhoven SE, Kirkevold M Engedal K, Kim H. 'Living a life in shades of grey': experiencing depressive symptoms in the acute phase after stroke. Journal of Advanced Nursing 2012;68:1726-37.

30. Kouwenhoven SE. Experiencing post-stroke depression. The nature and impact in a longitudinal perspective. Oslo: University of Oslo; 2012.

31. Horwitz AV, Wakenfield JC. The Loss of Sadness. How Psychiatry Transformed Normnal Sorrow Into Depressive Disorder. New York: Oxford University Press; 2007

32. Sandvik 0. Hva er sorg og hvordan kan den forstås? I Bugge K, Eriksen $\mathrm{H}$, Sandvik O, editors. Bergen: Fagbokforlaget 2011.

33. Niemeier JP, Burnett DM. No such thing as 'uncomplicated bereavement for patients in rehabilitation. Disability \& Rehabilitation. 2001;23:645-53.

34. Thomas KR, Siller J. Object loss, mourning, and adjustment to disability. Psychoanalytic Psychology. 1999;16:179-97.

35. Alaszewski A, Alaszewski H, Potter J. The bereavement model, stroke and rehabilitation: a critical analysis of the use of a psychological model in professional practice. Disability \& Rehabilitation. 2004;2618:1067-78

36. Niemeier J, Kennedy R, McKinley W, Cifu D. The Loss Inventory: A measure of emotional and cognitive responses to disability. Disability Rehabilitation. 2004;26:614-23.

37. Bonanno GA, Kaltman S. The varieties of grief experience. Clinical Psychology Review. 2001;21:705-34.

38. Clayton P. Bereavement. In: Paykel E, editor. Handbook of affective disorders. London: Churchill Livingstone; 1982. p. 15-46.

39. Zisook S, Shuchter SR. Depression through the first year after the death of a spouse. The American Journal of Psychiatry. 1991;148:1346-52.

40. Raingruber $B$. Client and provider perspectives regarding the stigma of and nonstigmatizing interventions for depression. Archives of Psychiatric Nursing. 2002;16:201-7.

41. Barney L, Griffiths K, Christensen $H$, Jorm A. Exploring the nature of stigmatising beliefs about depression and help-seeking: Implications for reducing stigma. BMC Public Health 2009;9.

42. Drummond A, Walker M. Generalisation of effects of leisure rehabilitation for stroke patients. British Journal of Occutpational Therapy. 1996;59:330-4. 43. Pound P, Gompertz P, Ebrahim S. A patient-centred study of the consequences of stroke. Clin Rehabil. 1998;12:338-47.

44. Sjögren K, Fugl-Meyer A. Adjustment to life after stroke. With special reference to sexual intercourse and leisure. J Psychosom Res. 1982;26:40917.

45. Nilsson I, Jansson L, Norberg A. To meet with a stroke: patients experiences and aspects seen through a screen of crises. Journal of Advanced Nursing. 1997;25:953-63.

46. Kvigne K, Kirkevold M, Gjengedal E. Fighting back-struggling to continue life and preserve the self following a stroke. Health Care for Women International. 2004;25:370-87.

47. Hilton EL. The meaning of stroke in elderly women: a phenomenological investigation. Journal of Gerontological Nursing. 2002;28:19-26.
48. Schwartz C, Sprangers M. Methodological approaches for assessing response shift in longitudinal quality of life research. Social Science and Medicine. 1999;48:1531-48.

49. Kringlen E. Psykiatriens samtidshistorie. Oslo: Universitetsforlaget; 2001

50. Ekeland T. Et nytt psykisk helsevern - ny kunnskap?: Norsk kompetansesenter for erfaringskunnskap i psykisk helse; 2011.

51. Ekeland T. Medikalisering - epistemologiske forutsetninger. In: Kolstad A, Kogstad R, editors. Psykologisering av sosiale problemer Medikalisering av psykiske lidelser Haugesund: Alpha Forlag; 2011

52. Nye R. The evolution of the concept of medicalization in the late twentieth century. Journal of History of the Behavioral Sciences. 2003;39:115-29.

53. Foucault M. Galskapens historie i opplysningens tidsalder. Oslo: Gyldendal; 2008.

54. Jørgensen C. Psykologien i senmoderniteten. København: Hans Reitzels Forlag; 2004.

55. Burton C, Gibbon B. Expanding the role of the stroke nurse: a pragmatic clinical trial. Journal of Advanced Nursing. 2005;52:640-50.

56. Bendz M. The first year of rehabilitation after a stroke - from two perspectives. Scandinavian Journal of Caring Sciences. 2003;17:215-22.

57. Kaufman SR. Toward a phenomenology of boundaries in medicine: chronic illness experience in the case of stroke. Topics in Stroke Rehabilitation. 2011;18:6-17.

58. Shapiro A. A story to create: stroke survivors' broken narratives. Top Stroke Rehabil 2011;18:18-23.

59. Rowe D. Depression 2 nd. ed. New York: Routledge; 1996.

60. Rowe F, Brand D, Jackson C, Price A, Walker L, Harrison S, et al. Visual impairment following stroke: do stroke patients require vision assessment? Age Ageing. 2009;38:188-93.

61. Donahue $A B$. Riding the mental health pendulum: mixed messages in the era of neurobiology and self-help movements. Social Work. 2000;45:42738. 